\title{
Percutaneous aortic and mitral valve repair - from bench testing to simulators and clinical data
}

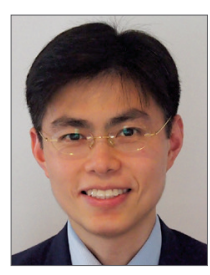

Paul T.L. Chiam*1,2, MBBS, MRCP; Huay Cheem Tan²,3, MBBS, MRCP

1. The Heart \& Vascular Centre, Mount Elizabeth Hospital, Singapore; 2. Yong Loo Lin School of Medicine, National University of Singapore; 3. National University Heart Centre, Singapore

This issue focuses mainly on valvular heart interventions, with manuscripts on transcatheter aortic valve implantation (TAVI), an old but (still) relevant topic of percutaneous mitral balloon valvuloplasty, percutaneous mitral valve repair with the MitraClip device, articles on a novel technique for peripheral artery intervention and coronary intervention, and a review of the knuckle wire technique in chronic total occlusion (CTO) percutaneous coronary intervention (PCI).

TAVI has become a standard of care for patients with severe aortic valve stenosis. Robust randomised trial data now spans across the entire patient risk spectrum ${ }^{1-4}$, and TAVI is increasingly performed in $\mathrm{Asia}^{5}$. Four sizes of the balloon-expandable SAPIEN 3 valve (Edwards Lifesciences Inc., Irvine, CA, USA) are currently available $-20 \mathrm{~mm}, 23 \mathrm{~mm}, 26 \mathrm{~mm}$ and $29 \mathrm{~mm}$. For the majority of patients, one of the above valve sizes would fall within the optimal range of their annulus measurements. In a significant minority of patients, the annulus size is in the "grey zone" between 2 THV sizes. The dilemma facing the TAVI operator in such a scenario is whether to use a smaller but overexpanded THV or a larger but underexpanded THV, based on considerations of sealing to prevent paravalvular leaks, optimising THV gradients, conduction disturbances (including the need for permanent pacemaker) and the risk of annular rupture.
It has been shown previously (using finite element analyses) that the peak stresses on the SAPIEN balloon-expandable THVs are at the commissural tips where the leaflets are attached to the stent frame, and this finding was consistent from the first- and second- to the third-generation SAPIEN THVs ${ }^{6-8}$. Previous bench studies also demonstrated that the THV leaflet and stent mechanical stresses increase with under expansion and increasing THV ellipticity and may affect THV durability,7,9-11.

In this issue of AsiaIntervention, Xuan et al describe the impact of using a smaller versus a larger $(23 \mathrm{~mm}$ vs $26 \mathrm{~mm}, 26 \mathrm{~mm}$ vs $29 \mathrm{~mm}$ ) balloon-expandable second-generation SAPIEN XT THV deployed to an area within the "grey zone" annulus area. Using finite element analyses, the two main findings were: 1) for annulus size within the grey zone, under-sizing a larger THV resulted in lower leaflet stresses than oversizing a smaller THV (e.g. $26 \mathrm{~mm}$ vs $23 \mathrm{~mm}$ and $29 \mathrm{~mm}$ vs $26 \mathrm{~mm}$ ). The stress distribution of the leaflets did not change significantly in an oversized smaller THV, whereas the stress distribution of the leaflets shifted towards lower levels in an undersized larger THV; and 2) for nominal (optimal) expansion, larger THVs experienced greater leaflet stresses. This is due to the fact that a larger THV has a larger cross-sectional area for the same pressure loading conditions. The corollary is that, if one were to translate this directly to the clinical setting, it 
implies that nominally expanded larger THVs are more likely to degenerate earlier; but for patients with annulus sizes in the grey zones, using a larger undersized THV would be superior to oversizing a smaller THV, as one could expect better durability with an undersized larger THV.

This study adds to our understanding of the stresses acting on the leaflets and stent frames of the SAPIEN balloon-expandable THV and demonstrates that for a given annulus size within the grey zone, choosing an underexpanded larger balloon-expandable THV may confer an advantage. The major limitation of this conclusion is that the SAPIEN XT THV is no longer in clinical use and one has to assume that the current third-generation balloon-expandable THV (SAPIEN 3) will have similar stresses with under-/overexpansion, which might not be the case. These data are modelled using computational software without direct measurement of leaflet stresses. In fact, an in vitro study of SAPIEN 3 THVs using accelerated wear testing showed excellent durability out to 5 years (200 million cycles) for non-nominally (under-/ over-) expanded THVs ${ }^{12}$.

Furthermore, loading conditions and THV stresses in actual clinical settings may differ. Intuitively, one could expect that underexpanding a larger THV would result in a higher residual gradient (with more patient-prosthesis mismatch) than overexpanding a smaller THV in a borderline size annulus. Yet actual clinical experience of underexpanding balloon-expandable THVs showed that valve haemodynamics and paravalvular regurgitation were similar to those which were nominally expanded ${ }^{13}$. Conversely, aggressively overexpanding a smaller THV may lead to impaired leaflet function and even leaflet damage in vitro ${ }^{14}$, although this was not seen in a clinical study with $11 \%$ to $13 \%$ overexpansion.

What is the clinician to make of these data? One needs to consider what would be the safest option for a patient with an annulus size in the borderline zone. Overexpansion of a smaller THV may achieve greater circularity of the THV and reduce paravalvular leak, but increase the risk of (fatal) annular rupture and the need for permanent pacemaker implantation, and may increase leaflet stress. Underexpansion of a larger THV, on the other hand, will reduce the risk of annular rupture and the need for a permanent pacemaker, and may reduce leaflet stress as demonstrated in the current study. For some patients, with heavily calcified left ventricular outflow tract and small, calcified ilio-femorals, neither of these may however, be good options and the use of a self-expanding THV would be the safest and most suitable choice.

Rheumatic heart disease (RHD), although declining in global incidence over the past few decades, is still relatively prevalent in many parts of $\mathrm{Asia}^{15}$. Mitral stenosis, the commonest valvular manifestation, is frequently encountered in developing countries. For patients with symptomatic mitral stenosis and favourable mitral valve morphology (mobile, thin leaflets, lack of subvalvular disease) percutaneous transvenous mitral commissurotomy (PTMC), also known as percutaneous mitral balloon valvotomy, has been shown to an effective treatment, with durable clinical and haemodynamic results comparable to surgical valvotomy ${ }^{15}$.

As the bulk of interventional cardiology work has shifted to coronary intervention, many interventional trainees (and cardiologists) are lacking in skills and experience with this technique. In this issue of the journal, Song et al describe a portable simulator using a 3D printed heart model for PTMC training. The authors found that the simulator significantly reduced the procedure time in simulation with increasing practice. The model also scored highly (by physician questionnaire) with regards to simulator utility and realism, and effect of training on PTMC performance. In particular, this simulator is able to train physicians in the two most critical steps of the PTMC procedure: the transseptal puncture and advancing the Inoue balloon across the mitral valve.

The main advantages of this $3 \mathrm{D}$ printed model compared to commercial simulators are its portability and ease of assembly/ transport, low cost, and no requirement for a power source - factors that are of importance for widespread use in the developing world. It is thus easily scalable to be used in many centres in developing countries. The information that is lacking from this study is how this low-cost model compares to commercially available simulators. Future studies could be designed to assess this.

This model may also be useful to help refresh the skills of operators in developed countries where, despite the low incidence of rheumatic mitral stenosis, there is the occasional need to perform PTMC. With some modifications, it would not be far-fetched to imagine a scenario where this low-cost model could also be used for training in percutaneous mitral valve repair procedures.

Surgical mitral valve repair or replacement has been the standard of care for patients with severe mitral regurgitation $(\mathrm{MR})^{15}$. Percutaneous mitral valve repair with the MitraClip ${ }^{\mathrm{TM}}$ (Abbott Vascular, Santa Clara, CA, USA) is an alternative therapy for certain patients with severe MR. In the only randomised trial comparing percutaneous repair to surgery (EVEREST II trial), the MitraClip device was shown to be safer (driven mainly by fewer blood transfusions; equal death or stroke rates) but less efficacious (more residual/recurrent MR) than surgery, although there were similar improvements in functional status ${ }^{16}$. Only two other randomised trials of the MitraClip device are available, but both trials compared percutaneous repair versus medical therapy in patients with severe functional MR, with conflicting results ${ }^{17,18}$.

Compared to TAVI, where there are seven published randomised trials comparing the transcatheter option to surgery, the randomised data of the MitraClip device compared to surgical therapy are limited. More evidence is required guide physicians on the best treatment option for patients with severe MR.

In this issue of the journal, Wang et al perform a meta-analysis of available trials comparing the MitraClip device versus surgery. After a literature search and review, only nine studies were relevant, of which only one (EVEREST II) was a randomised trial and the remaining eight were retrospective cohort studies. The total number of patients in this meta-analysis was only 1,171 ; in 
contrast, the recent PARTNER 3 randomised trial comparing TAVI versus surgery had 1,000 patients ${ }^{4}$. The major limitations of this study are its moderate sample size and inherent biases present in observational studies.

Nevertheless, this current study does provide information on a larger number of patients undergoing MitraClip device therapy compared to surgery for severe MR (both degenerative and functional). Patients receiving the MitraClip device were older, had more coronary artery disease and previous coronary artery bypass surgery, and had higher Logistic EuroSCOREs (MitraClip 23\% vs surgery 11\%). Despite a higher baseline risk profile, the operative mortality was similar (MitraClip 3\% vs surgery 5\%), which demonstrates that the MitraClip device therapy is the safer option. Longer-term mortality at one and three years were also similar between the two arms. Complications differed, with patients undergoing MitraClip device therapy having higher rates of early and late significant MR, and more cardiovascular readmissions, whereas patients undergoing surgery had higher rates of in-hospital bleeding and pacemaker implantation. These results are broadly similar to the findings of the EVEREST II trial - percutaneous repair with the MitraClip device is safer but less efficacious than surgery. Thus, MitraClip device therapy is ideal for patients with degenerative MR who are at elevated surgical risk, as the periprocedural complications are few and patients derive symptomatic benefit equal to that of higher-risk surgery. Whether MitraClip device therapy is useful in patients with functional MR is more uncertain, although the data suggest that a selected subgroup of patients are likely to derive benefit ${ }^{17,18}$.

Despite having a low complication rate, adverse events during or after MitraClip device therapy can occur. In this issue of the journal, Wong et al share a case of successful snaring and femoral vein cutdown removal of a MitraClip that became partially detached after release of the lock line, and completely detached after deployment pin release. Chrissoheris et al describe a complex case with three previous MitraClips and severe MR emanating from an area between the clips and haemodynamically significant right to left shunt from an iatrogenic atrial septal defect. The gap between the clips was "sealed" with an AMPLATZERTM Vascular Plug II (Abbott Vascular) and the iatrogenic ASD was closed with a AMPLATZER ${ }^{\text {TM }}$ Septal Occluder (Abbott Vascular) with symptomatic improvement.

PCI for CTOs is an area where extensive advancements have taken place over the past decade. Sessions on CTO PCI are usually oversubscribed, attesting to the interest in this topic. In this issue of the journal, Reddy et al review the knuckle wire technique for CTO PCI. Their review is a comprehensive yet simple stepby-step guide on the technique and is useful for interventionalists who perform or are gaining experience in complex CTO PCI. The other article on PCI by Basavarajaiah et al describes a case where direct stenting resulted in an underexpanded stent that could not be further dilated with a non-compliant high-pressure balloon. The authors placed a coronary intravascular lithotripsy "shock wave" balloon within the stent which succeeded in optimally expanding the stent. This case demonstrated that such a manoeuvre was safe with a durable clinical outcome at 12 months.

The final article in this issue moves on to peripheral artery intervention, where Nishimoto et al describe a novel technique to cross an eccentric bulky calcified nodule in the popliteal artery using the TruPath ${ }^{\mathrm{TM}}$ (diamond coated tip) wire (Boston Scientific, Marlborough, MA, USA). With this technique, the authors were able to cross the lesion centrally, resulting in a well-expanded vessel. A conventional guide wire would have crossed the lesion to the side of this eccentric calcium nodule and impaired the ability to fully dilate the stenosis. This technique would be of interest to physicians performing peripheral interventions but is likely to be limited by device availability and familiarity, and additional cost. Use of a peripheral intravascular lithotripsy "shock wave" balloon may be a simpler option.

We do hope readers will benefit from reading this issue of AsiaIntervention and find the articles useful in their practice.

\section{References}

1. Leon MB, Smith CR, Mack M, Miller DC, Moses JW, Svensson LG, Tuzcu EM, Webb JG, Fontana GP, Makkar RR, Brown DL, Block PC, Guyton RA, Pichard AD, Bavaria JE, Herrmann HC, Douglas PS, Petersen JL, Akin JJ, Anderson WN, Wang D, Pocock S; PARTNER Trial Investigators. Transcatheter aortic-valve implantation for aortic stenosis in patients who cannot undergo surgery. N Engl J Med. 2010;363:1597-607.

2. Smith CR, Leon MB, Mack MJ, Miller DC, Moses JW, Svensson LG, Tuzcu EM, Webb JG, Fontana GP, Makkar RR, Williams M, Dewey T, Kapadia S, Babaliaros V, Thourani VH, Corso P, Pichard AD, Bavaria JE, Herrmann HC, Akin JJ, Anderson WN, Wang D, Pocock SJ; PARTNER Trial Investigators. Transcatheter versus surgical aortic-valve replacement in high-risk patients. N Engl J Med. 2011;364:2187-98.

3. Leon MB, Smith CR, Mack MJ, Makkar RR, Svensson LG, Kodali SK, Thourani VH, Tuzcu EM, Miller DC, Herrmann HC, Doshi D, Cohen DJ, Pichard AD, Kapadia S, Dewey T, Babaliaros V, Szeto WY, Williams MR, Kereiakes D, Zajarias A, Greason KL, Whisenant BK, Hodson RW, Moses JW, Trento A, Brown DL, Fearon WF, Pibarot P, Hahn RT, Jaber WA, Anderson WN, Alu MC, Webb JG; PARTNER 2 Investigators. Transcatheter or Surgical Aortic-Valve Replacement in Intermediate-Risk Patients. N Engl J Med. 2016;374:1609-20.

4. Mack MJ, Leon MB, Thourani VH, Makkar R, Kodali SK, Russo M, Kapadia SR, Malaisrie SC, Cohen DJ, Pibarot P, Leipsic J, Hahn RT, Blanke P, Williams MR, McCabe JM, Brown DL, Babaliaros V, Goldman S, Szeto WY, Genereux P, Pershad A, Pocock SJ, Alu MC, Webb JG, Smith CR; PARTNER 3 Investigators. Transcatheter Aortic-Valve Replacement with a BalloonExpandable Valve in Low-Risk Patients. N Engl J Med. 2019;380: 1695-705.

5. Chiam PTL. Transcatheter aortic valve implantation in Asia: the first decade. EuroIntervention. 2018;14:35-7. 
6. Xuan Y, Krishnan K, Ye J, Dvir D, Guccione JM, Ge L, Tseng EE. Stent and leaflet stresses in a 26-mm first-generation balloonexpandable transcatheter aortic valve. J Thorac Cardiovasc Surg. 2017;153:1065-73.

7. Xuan Y, Krishnan K, Ye J, Dvir D, Guccione JM, Ge L, Tseng EE. Stent and Leaflet Stresses in 29-mm Second-Generation BalloonExpandable Transcatheter Aortic Valve. Ann Thorac Surg. 2017; 104:773-81.

8. Xuan Y, Dvir D, Wang Z, Mizoguchi T, Ye J, Guccione JM, Ge L, Tseng EE. Stent and leaflet stresses in 26-mm, third-generation, balloon-expandable transcatheter aortic valve. J Thorac Cardiovasc Surg. 2019;157:528-36.

9. Sun W, Li K, Sirois E. Simulated elliptical bioprosthetic valve deformation: implications for asymmetric transcatheter valve deployment. J Biomech. 2010;43:3085-90.

10. Abbasi M, Azadani AN. Leaflet stress and strain distributions following incomplete transcatheter aortic valve expansion. J Biomech. 2015;48:3663-71.

11. Martin C, Sun W. Comparison of transcatheter aortic valve and surgical bioprosthetic valve durability: A fatigue simulation study. J Biomech. 2015;48:3026-34.

12. Sathananthan J, Hensey M, Landes U, Alkhodair A, Saiduddin A, Sellers S, Cheung A, Lauck S, Blanke P, Leipsic J, Ye J, Wood DA, Webb JG. Long-Term Durability of Transcatheter Heart Valves: Insights From Bench Testing to 25 Years. JACC Cardiovasc Interv. 2020;13:235-49.

13. Barbanti M, Leipsic J, Binder R, Dvir D, Tan J, Freeman M, Norgaard B, Hansson N, Cheung A, Ye J, Yang TH, Maryniak K, Raju R, Thompson A, Blanke P, Lauck S, Wood D, Webb J. Underexpansion and ad hoc post-dilation in selected patients undergoing balloon-expandable transcatheter aortic valve replacement. J Am Coll Cardiol. 2014;63:976-81.
14. Sathananthan J, Sellers S, Barlow A, Fraser R, Stanova V, Cheung A, Ye J, Alenezi A, Murdoch DJ, Hensey M, Dvir D, Blanke P, Rieu R, Wood D, Pibarot P, Leipsic J, Webb J. Overexpansion of the SAPIEN 3 Transcatheter Heart Valve: An Ex Vivo Bench Study. JACC Cardiovasc Interv. 2018;11:1696-705. 15. Otto CM, Nishimura RA, Bonow RO, Carabello BA, Erwin JP 3rd, Gentile F, Jneid H, Krieger EV, Mack M, McLeod C, O'Gara PT, Rigolin VH, Sundt TM 3rd, Thompson A, Toly C. 2020 ACC/AHA Guideline for the Management of Patients With Valvular Heart Disease: Executive Summary: A Report of the American College of Cardiology/American Heart Association Joint Committee on Clinical Practice Guidelines. Circulation. 2021;143:e35-71. Erratum in: Circulation. 2021;143:e784.

16. Feldman T, Foster E, Glower DD, Kar S, Rinaldi MJ, Fail PS, Smalling RW, Siegel R, Rose GA, Engeron E, Loghin C, Trento A, Skipper ER, Fudge T, Letsou GV, Massaro JM, Mauri L; EVEREST II Investigators. Percutaneous repair or surgery for mitral regurgitation. N Engl J Med. 2011;364:1395-406. Erratum in: N Engl J Med. 2011;365:189.

17. Obadia JF, Messika-Zeitoun D, Leurent G, Iung B, Bonnet G, Piriou N, Lefèvre T, Piot C, Rouleau F, Carrié D, Nejjari M, Ohlmann P, Leclercq F, Saint Etienne C, Teiger E, Leroux L, Karam N, Michel N, Gilard M, Donal E, Trochu JN, Cormier B, Armoiry X, Boutitie F, Maucort-Boulch D, Barnel C, Samson G, Guerin P, Vahanian A, Mewton N; MITRA-FR Investigators. Percutaneous Repair or Medical Treatment for Secondary Mitral Regurgitation. N Engl J Med. 2018;379:2297-306.

18. Stone GW, Lindenfeld J, Abraham WT, Kar S, Lim DS, Mishell JM, Whisenant B, Grayburn PA, Rinaldi M, Kapadia SR, Rajagopal V, Sarembock IJ, Brieke A, Marx SO, Cohen DJ, Weissman NJ, Mack MJ; COAPT Investigators. Transcatheter Mitral-Valve Repair in Patients with Heart Failure. $N$ Engl J Med. 2018;379:2307-18. 